\title{
High incidence of surgical site infection may be related to suboptimal case selection for non-selective arterial embolization during resuscitation of patients with pelvic fractures: a retrospective study
}

Chih-Yang Lai', I-Chuan Tseng ${ }^{1}$, Chun-Yi Su², Yung-Heng Hsu' ${ }^{1}$, Ying-Chao Chou', Huan-Wu Chen ${ }^{3}$ and Yi-Hsun $\mathrm{Yu}^{1 *}$ (D)

\begin{abstract}
Background: In most institutions, arterial embolization (AE) remains a standard procedure to achieve hemostasis during the resuscitation of patients with pelvic fractures. However, the actual benefits of AE are controversial. In this study, we aimed to explore AE-related outcomes following resuscitation at our center and to assess the predictive value of contrast extravasation (CE) during computed tomography (CT) for patients with hemodynamically unstable closed pelvic fractures.

Methods: We retrospectively reviewed data from patients who were treated for closed pelvic fractures at a single center between 2014 and 2017. Data regarding the AE and clinical parameters were analyzed to determine whether poor outcomes could be predicted.

\footnotetext{
* Correspondence: alanyu1007@gmail.com

'Department of Orthopedic Surgery, Musculoskeletal Research Center, Chang Gung Memorial Hospital, Linkou branch, and Chang Gung University 33302, Tao-Yuan, Taiwan. 5, Fu-Hsin St. Kweishan, 33302 Tao-Yuan, Taiwan Full list of author information is available at the end of the article
}

C C The Author(s). 2020 Open Access This article is licensed under a Creative Commons Attribution 4.0 International License, which permits use, sharing, adaptation, distribution and reproduction in any medium or format, as long as you give appropriate credit to the original author(s) and the source, provide a link to the Creative Commons licence, and indicate if changes were made. The images or other third party material in this article are included in the article's Creative Commons licence, unless indicated otherwise in a credit line to the material. If material is not included in the article's Creative Commons licence and your intended use is not permitted by statutory regulation or exceeds the permitted use, you will need to obtain permission directly from the copyright holder. To view a copy of this licence, visit http://creativecommons.org/licenses/by/4.0/. The Creative Commons Public Domain Dedication waiver (http://creativecommons.org/publicdomain/zero/1.0/) applies to the data made available in this article, unless otherwise stated in a credit line to the data. 
(Continued from previous page)

Results: During the study period, 545 patients were treated for closed pelvic fractures, including 131 patients who underwent angiography and 129 patients who underwent AE. Nonselective bilateral internal iliac artery embolization (nBIIAE) was the major AE strategy (74\%). Relative to the non-AE group, the AE group had higher values for injury severity score, shock at hospital arrival, and unstable fracture patterns. The AE group was also more likely to require osteosynthesis and develop surgical site infections (SSIs). Fourteen patients (10.9\%) experienced late complications following the AE intervention, including 3 men who had impotence at the 12-month follow-up visit and 11 patients who developed SSIs after undergoing AE and osteosynthesis (incidence of SSI: 11/75 patients, 14.7\%). Nine of the 11 patients who developed SSI after AE had undergone nBIIAE. The positive predictive value of CE during CT was 29.6\%, with a negative predictive value of $91.3 \%$. Relative to patients with identifiable CE, patients without identifiable CE during CT had a higher mortality rate (30.0\% vs. 11.0\%, $p=0.03$ ).

Conclusion: Performing AE for pelvic fracture-related hemorrhage may not be best practice for patients with no CE detected during $\mathrm{CT}$ or for unstable patients who do not respond to resuscitation after exclusion of other sources of hemorrhage. Given the high incidence of SSI following nBIIAE, this procedure should be selected with care. Given their high mortality rate, patients without CE during imaging might be considered for other hemostasis procedures, such as preperitoneal pelvic packing.

Keywords: Trauma of pelvis, Infection, Major trauma management, Resuscitation, And critical care

\section{Background}

Pelvic fractures can often result in potentially lethal hemorrhage and hypotension $[1,2]$. Thus, hemodynamically unstable patients with pelvic fractures present a major challenge for acute care and orthopedic surgeons, and such patients are best managed by a multi-disciplinary team [3]. However, the appropriate acute management of hemodynamically unstable patients with pelvic fractures remains controversial. Arterial embolization (AE) and preperitoneal pelvic packing (PPP) are common procedures in this setting, although there is no conclusive evidence for the superiority of either procedure $[2,4,5]$.

Some reports have described $\mathrm{AE}$ as an effective procedure for managing pelvic fracture-related retroperitoneal arterial hemorrhage $[6,7]$. AE is a classical treatment and remains a standard hemostatic procedure in many institutions [79], including our institution, based on reports regarding its efficacy during the management of pelvic fracture-related hemorrhage $[8,10]$. However, $\mathrm{AE}$ is associated with various complications, including inadequate hemostasis, gluteal muscle necrosis, and surgical site infection (SSI) $[11,12]$. Therefore, as an observation of contrast extravasation (CE) during computed tomography (CT) [13] is unreliable as a sole basis for selecting AE, additional information is needed to help determine when $\mathrm{AE}$ can help provide optimal outcomes. This study aimed to explore AE-related outcomes following resuscitation at our center and to assess the predictive value of $\mathrm{CE}$ during $\mathrm{CT}$ for patients with hemodynamically unstable closed pelvic fractures.

\section{Methods}

At our institution, AE is a standard procedure for pelvic fracture-related hemorrhage and is performed when $\mathrm{CE}$ is detected during contrast-enhanced CT or for unstable patients who do not respond to resuscitation after the exclusion of other sources of hemorrhage. Angiography is initially performed to evaluate the abdominal aorta, lumbar arteries, bilateral common iliac arteries, bilateral external iliac arteries, and bilateral internal iliac arteries. When arterial bleeding is detected or suspected, the first embolization material is generally gelfoam (SPONGOSTAN, Ethicon Inc., Belgium), and bleeding is re-checked $5 \mathrm{~min}$ later. If an aneurysm persists or CE recurs, permanent embolization is performed using metal coils (Tornado Embolization Coils, Cook Inc., USA or VortX-18 Coils, Boston Scientific, USA). Selective or non-selective embolization is performed at the discretion of the interventional radiologist. After any $\mathrm{AE}$, the patient is admitted to the intensive care unit or the ward, depending on the clinical requirements. Osteosynthesis is then performed for pelvic ring injuries after the patient's clinical condition has stabilized. During the study period, resuscitative endovascular balloon occlusion of the aorta was not available for managing these patients at our center.

We retrospectively reviewed trauma registry data, including clinical and imaging records, from all cases of pelvic fracture that were treated at our center between January 2014 and December 2017. The study's retrospective protocol was approved by our institutional review board (IRB: 201802139B0). Patients were excluded if they had an isolated acetabular fracture, were dead upon arrival, were diagnosed with a pelvic fracture without imaging, or had undergone $\mathrm{AE}$ as a hemostatic procedure targeting non-pelvic regions. All patients with pelvic fractures were resuscitated and managed according to our established protocol, which 
was based on the Advanced Trauma Life Support guidelines.

The patients' demographic characteristics, injury severity score (ISS), fracture patterns, $\mathrm{AE}$ details, and $\mathrm{AE}$ related complications were recorded. Complications were defined as adverse responses or unexpected conditions that were likely related to the AE procedure. We defined an SSI as a post-osteosynthesis wound complication, which yielded a positive bacterial culture. Information regarding impotence in men was self-reported at the 12-month follow-up visit.

Data were analyzed using SPSS software (version 18.0; SPSS Inc., Chicago, IL). Continuous variables were compared using the t-test, and categorical variables were compared using the chi-squared test and Fisher's exact test. Predictive analyses were performed to determine whether the presence of $\mathrm{CE}$ during $\mathrm{CT}$ could be used to predict clinical outcomes.

\section{Results}

During the 48-month study period, we identified 545 patients with closed pelvic fractures who underwent resuscitation and treatment (Table 1). Traffic accident

Table 1 Demographic characteristics of patients with pelvic fracture during 2014-2017 at our institution

\begin{tabular}{ll}
\hline Total number of patients & 545 \\
\hline Mean age, years & $46.2 \pm 21.6$ \\
Sex, $n$ (\%) & \\
$\quad$ Male & $267(49.0 \%)$ \\
$\quad$ Female & $278(51.0 \%)$ \\
Trauma mechanism, $n$ (\%) & \\
$\quad$ Traffic accident & $383(70.2 \%)$ \\
Falling from height & $145(26.6 \%)$ \\
Other & $17(3.2 \%)$ \\
Mean Injury Severity Score & $17.4 \pm 12.2$ \\
Shock on arrival, $n$ (\%) & $112(20.6 \%)$ \\
Fracture classification, $n$ (\%) + & \\
Stable ring & $277(50.8 \%)$ \\
Partially stable ring & $113(20.7 \%)$ \\
Unstable ring & $155(28.5 \%)$ \\
Imaging used to evaluate arterial bleeding, $n(\%)$ & \\
Computed tomography & $545(100 \%)$ \\
Angiography & $131(24.0 \%)$ \\
Arterial embolization, $n$ (\%) & \\
No & \\
Yes & $416(76.3 \%)$ \\
Morteosynthesis for pelvic fracture, $n$ (\%) $n$ (\%) & $129(23.7 \%)$ \\
\hline & $211(38.7 \%)$ \\
\hline
\end{tabular}

† The classification of the pelvic fracture was based on the AO/OTA classification (2018 revision) was the most common injury mechanism (70.2\%). Initial clinical assessments revealed that 112 patients (20.6\%) were in shock at the initial presentation and required resuscitation and blood transfusions. After resuscitation, 49 patients $(43.8 \%)$ were identified as responders, and the remaining patients did not initially respond to resuscitation. The CT assessments revealed that 390 patients (71.5\%) had partially stable or unstable ring patterns. Angiography was performed for 131 patients (24\%) who were unresponsive to resuscitation or who had $\mathrm{CE}$ during the CT examination. There were no complications during or immediately after the angiography procedure, and $\mathrm{AE}$ was performed for 129 of the 131 patients (98.5\%) who underwent angiography (Table 2).

The average time from the order to the angiography procedure was $63.8 \pm 44.7 \mathrm{~min}$. Ninety-seven patients (74.0\%) underwent non-selective bilateral internal iliac artery embolization (nBIIAE) using gelfoam as the filling material. Only 11 of the 129 patients (8.5\%) underwent AE using metal coils. Fourteen patients (10.9\%) experienced late complications after the $\mathrm{AE}$ intervention, including 3 men who had impotence at the 12-month follow-up visit and 11 patients who developed SSIs after the AE and osteosynthesis (Fig. 1). The incidence of SSIs among patents who underwent $\mathrm{AE}$ and osteosynthesis was $14.7 \%$ ( $11 / 75$ patients). Among the 11 patients, 6 had Morel-Lavallée lesions, and 2 had open fractures

Table 2 Characteristics of the patients who underwent arterial embolization

\begin{tabular}{ll}
\hline Total patients, $\mathrm{n}$ & 129 \\
\hline Mean time from order to procedure, min & $63.8 \pm 44.7$ \\
Shock on arrival, $n$ (\%) & $90(69.7 \%)$ \\
Non-response to resuscitation, $n$ (\%) & $47(36.4 \%)$ \\
Contrast extravasation, $\mathrm{n}(\%)$ & \\
$\quad$ During CT & $107(82.9 \%)$ \\
During angiography & $34(26.3 \%)$ \\
Location of AE, $\mathrm{n}(\%)$ & \\
BllA & $97(74.0 \%)$ \\
RIIA & $17(12.9 \%)$ \\
LIIA & $15(11.8 \%)$ \\
Material used for embolization, $\mathrm{n}(\%)$ & $118(91.4 \%)$ \\
Gelfoam & $11(8.6 \%)$ \\
Metal coils & $2388.1 \pm 2633.6$ \\
Mean blood transfusion, $\mathrm{mL}$ & $75(58.1 \%)$ \\
Osteosynthesis surgery, $\mathrm{n}(\%)$ & \\
AE-related complications, $\mathrm{n}(\%)$ & 3 \\
Impotence in men & 11 \\
Surgical site infection & \\
\hline CT computed tomography $\mathrm{AE}$ ateial &
\end{tabular}

$C T$ computed tomography, $A E$ arterial embolization, BIIA bilateral internal iliac arteries, RIIA right internal iliac artery, LIIA left internal iliac artery 


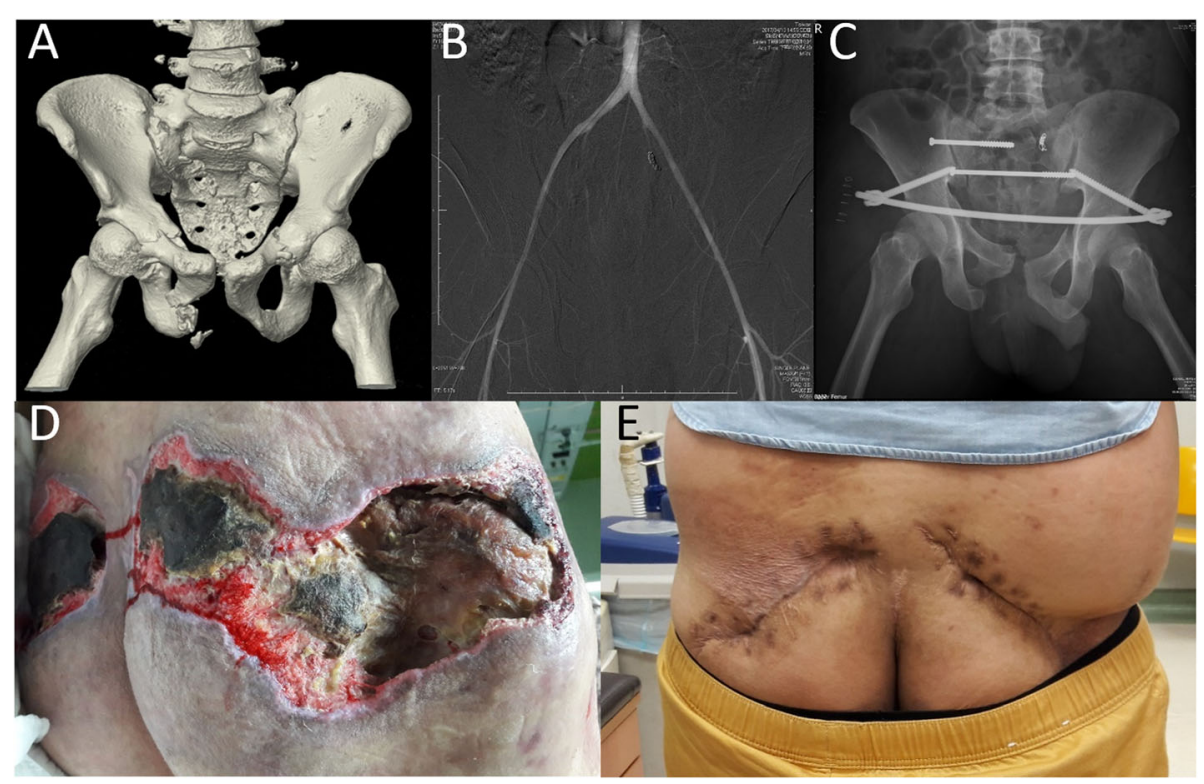

Fig. 1 A case with surgical site infection following trans-arterial embolization and osteosynthesis for pelvic ring injury. a Computed tomography revealed an AO/OTA B3.1 pelvic ring injury. b Bilateral internal iliac artery trans-arterial embolization was performed using gelfoam (right side) and metal coil (left side). c Radiographic findings after the osteosynthesis. $\mathbf{d}$ Significant bilateral gluteus maximus necrosis was observed at 1 month after the trans-arterial embolization. e Final appearance after treatment for the soft-tissue defect

(both involving Faringer zone I) [14]. Nine of the 11 patients with SSIs $(81.8 \%)$ had undergone nBIIAE. Methicillin-resistant Staphylococcus aureus was the most common bacterium causing SSIs (Table 3).

Table 4 shows comparisons between patients who did and did not undergo AE. Patients who underwent AE had a higher ISS (26.1 vs. $14.5, p=0.01)$, a greater likelihood of being in shock upon arrival $(68.2 \%$ vs. $5.3 \%, p=$ 0.001 ), a higher likelihood of having an unstable pelvic fracture pattern $(55.9 \%$ vs. $19.9 \%, \mathrm{p}=0.001)$, and a higher likelihood of undergoing osteosynthesis $(57.3 \%$ vs. $32.9 \%, \mathrm{p}=0.001)$. The $\mathrm{AE}$ group also had significantly higher rates of impotence in men $(4.8 \%$ vs. $0.6 \%, p=$ $0.036)$ and SSIs $(14.7 \%$ vs. $3.7 \%, p=0.006)$.

Among the 129 patients who underwent AE, 109 patients $(84.5 \%)$ had evidence of arterial bleeding at the time of the CT scan. Therefore, the value of AE was evaluated on the basis the characteristics of patients with and without identifiable CE during CT (Table 5). No significant inter-group differences were detected in initial shock status, response to resuscitation, age, sex, ISS, time to $\mathrm{AE}$, fracture classification, volume of blood transfusion, or rate of repeat AE. However, patients without identifiable CE during CT or angiography had a significantly higher 1-week in-hospital mortality rate than patients with identifiable CE $(30.0 \%$ vs. $11.0 \%, p=$ $0.03)$.

One of the indications for $\mathrm{AE}$ in our institution was the presence of $\mathrm{CE}$ during $\mathrm{CT}$. Therefore, we examined the relationship between identifiable bleeding during $\mathrm{CT}$ or during angiography (the standard for comparison) to evaluate the effectiveness of CT for assessing arterial bleeding in patients with unstable pelvic fractures. We used the angiography results as a standard baseline to examine the predictive value of CT examination. All 131 patients who underwent angiography had undergone CT examination upon their emergency department arrival. The CT examination revealed retroperitoneal bleeding in $108 / 131$ patients $(82.4 \%)$, although CE during angiography was only identified in 34/131 patients (26\%). Among the 34 patients with CE during angiography, 32 patients (94.2\%) had CE during the CT examination. Predictive analysis revealed that $\mathrm{CE}$ during $\mathrm{CT}$ had a sensitivity of $94.1 \%$, a specificity of $21.6 \%$, a positive predictive value (PPV) of $29.6 \%$, and a negative predictive value (NPV) of $91.3 \%$.

\section{Discussion}

Pelvic fractures may be accompanied by hemorrhage, which can lead to hemodynamic instability and death. At our institution, AE intervention is a standard procedure in this setting and is associated with good bleeding control outcomes $[8,10]$. Furthermore, delayed angiography in these patients may be associated with poor outcomes $[8,15,16]$. Technological improvements and increased availability have led to an increasing number of vascular injuries being identified during CT examinations, although recent studies have indicated that imaging-based evidence of $\mathrm{CE}$ does not necessarily indicate a need for $\mathrm{AE}$ to control bleeding [4, 17-19]. Thus, 


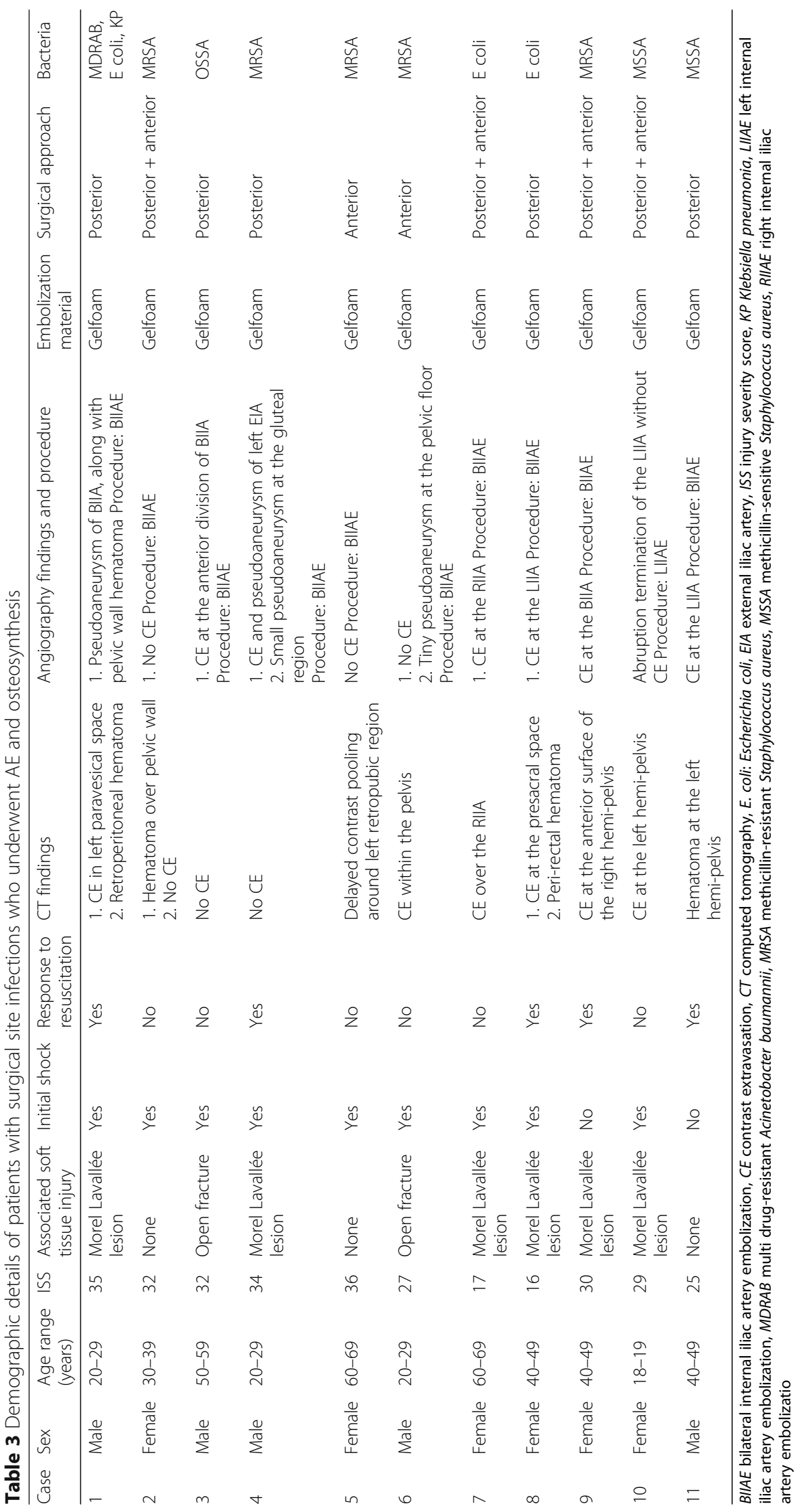


Table 4 Comparison of patients who did and did not undergo arterial embolization

\begin{tabular}{|c|c|c|c|}
\hline & No embolization $(n=416)$ & Arterial embolization $(n=129)$ & $p$-value \\
\hline \multicolumn{4}{|l|}{ Sex, $n(\%)$} \\
\hline Male & 205 (49.2\%) & $62(48.0 \%)$ & \multirow[t]{2}{*}{0.85} \\
\hline Female & $211(50.8 \%)$ & $67(52.0 \%)$ & \\
\hline Mean age, years & $45.5 \pm 21.1$ & $48.3 \pm 22.5$ & 0.25 \\
\hline Shock on arrival, $n(\%)$ & $22(5.3 \%)$ & $88(68.2 \%)$ & 0.001 \\
\hline Mean ISS & $14.5 \pm 10.7$ & $26.1 \pm 12.0$ & 0.01 \\
\hline \multicolumn{4}{|l|}{ Fracture classification, $n(\%) \dagger$} \\
\hline Stable pelvic ring & $245(58.9 \%)$ & $32(24.8 \%)$ & \multirow[t]{3}{*}{0.001} \\
\hline Partially unstable pelvic ring & $88(21.2 \%)$ & $25(19.3 \%)$ & \\
\hline Completely unstable pelvic ring & $83(19.9 \%)$ & $72(55.9 \%)$ & \\
\hline Surgery for pelvic fracture, $n(\%)$ & $136(32.6 \%)$ & $75(58.1 \%)$ & 0.001 \\
\hline \multicolumn{4}{|l|}{ Complications, $n$ (\%) } \\
\hline Impotence in men & $1(0.6 \%)$ & $3(4.9 \%)$ & 0.036 \\
\hline Surgical site infection & $5(3.7 \%)$ & $11(14.7 \%)$ & 0.006 \\
\hline Mortality, n (\%) & $5(1.2 \%)$ & $18(13.7 \%)$ & 0.001 \\
\hline
\end{tabular}

TThe classification of the pelvic fracture was based on the AO/OTA classification (2018 revision)

ISS injury severity score

hasty AE following pelvic fracture might not be an optimal step during the busy resuscitation process. Although $\mathrm{AE}$ can be promptly performed at our center (in a mean time of $60 \mathrm{~min}$ from order to procedure), the main diagnostic tool was CT, which had a low PPV, and the high incidence of SSIs following nBIIAE was suboptimal. For example, $82.4 \%$ of patients in the $\mathrm{AE}$ group exhibited signs of arterial bleeding during the CT examination, while only $26 \%$ of patients exhibited signs of CE during angiography. This corresponds to a PPV of only $29.6 \%$

Table 5 Comparison of patients who underwent arterial embolization with and without evidence of contrast extravasation during computed tomography

\begin{tabular}{|c|c|c|c|}
\hline & Evidence of CE $(n=109)$ & No evidence of CE $(n=20)$ & $p$-value \\
\hline Sex, $n(\%)$ & & & 0.47 \\
\hline Male & $54(49.5 \%)$ & $8(40.0 \%)$ & \\
\hline Female & $55(50.5 \%)$ & $12(60.0 \%)$ & \\
\hline Mean age, years & $48.1 \pm 22.9$ & $50.1 \pm 20.7$ & 0.34 \\
\hline Mean ISS & $26.2 \pm 12.5$ & $28.4 \pm 9.8$ & 0.13 \\
\hline Time from order to angiography, min & $64.6 \pm 47.2$ & $62.9 \pm 30.7$ & 0.67 \\
\hline Repeat $A E, n(\%)$ & $3(2.8 \%)$ & $2(10.0 \%)$ & 0.17 \\
\hline Fracture classification, n (\%) & & & 0.68 \\
\hline Stable ring & $30(27.5 \%)$ & $6(30.0 \%)$ & \\
\hline Partially stable ring & $32(29.3 \%)$ & $4(20.0 \%)$ & \\
\hline Unstable ring & $47(43.2 \%)$ & $10(50.0 \%)$ & \\
\hline Mean blood transfusion (mL) & $2348.1 \pm 2727.0$ & $2606.0 \pm 2097.2$ & 0.25 \\
\hline Embolization material & & & 0.23 \\
\hline Gelfoam & $101(92.7 \%)$ & $17(85.0 \%)$ & \\
\hline Metal coils & $8(7.3 \%)$ & $3(15.0 \%)$ & \\
\hline Osteosynthesis for pelvic fracture, n (\%) & $62(56.9 \%)$ & $13(65.0 \%)$ & 0.32 \\
\hline Embolization of BlIA, n (\%) & $82(75.2 \%)$ & $15(75.0 \%)$ & 0.59 \\
\hline Mortality, n (\%) & $12(11.0 \%)$ & $6(30.0 \%)$ & 0.03 \\
\hline
\end{tabular}

CE contrast extravasation, ISS injury severity score, $A E$ arterial embolization, BIIA bilateral internal iliac arteries 
for the use of CT to detect arterial injury in patients with pelvic fractures, which is similar to the results from previous studies $[13,20]$. We suspect that it may be difficult to differentiate between bone marrow and arterioles as the source of contrast extravasation during CT examination soon after a pelvic fracture, and our results suggest that evidence of $\mathrm{CE}$ during $\mathrm{CT}$ may not be a suitable major indication for $\mathrm{AE}$, despite this being previously recommended [7, 21]. Dreizin et al. [22] have suggested that the use of $\mathrm{AE}$ should be guided instead by the hematoma volume when arterial bleeding is detected during CT. We believe that angiography and $\mathrm{AE}$ should be performed more selectively, perhaps on the basis of non-response to resuscitation, a continuing decrease in hemoglobin concentration without evidence of bleeding from other sources, and the absence of arterial blush during CT.

Non-selective embolization is considered a hemostatic procedure for hemodynamically unstable patients with pelvic fractures $[7,23]$, although recent studies have focused on selective or super-selective embolization to decrease the negative effects of non-selective embolization in cases of vasospasm or rich collateral arterial networks within the pelvis $[24,25]$. Thus, we evaluated the outcomes of different $\mathrm{AE}$ strategies, given the fact that $\mathrm{AE}$ interventions might be accompanied by a high complication rate after these patients undergo osteosynthesis to treat their unstable pelvis. The present study revealed that $74 \%$ of patients underwent nBIIAE as their $\mathrm{AE}$ intervention, and 9 of 11 patients who developed SSIs after $\mathrm{AE}$ and osteosynthesis had undergone nBIIAE. Local soft tissue injuries after high-energy trauma, such as Morel-Lavallée lesions, might have contributed to the incidence of SSIs, although it would also be prudent to consider the potential contribution of nBIIAE.

Contrast-enhanced CT scans have become routine at many institutions, including ours, to detect arterial bleeding within the pelvis [26]. However, relative to angiography as the gold standard, CT had a low PPV and a high NPV for detecting arterial bleeding. In addition, we observed that patients without signs of CE during imaging had a significantly higher mortality rate after $\mathrm{AE}$, relative to patients with signs of $\mathrm{CE}$ during $\mathrm{CT}$ $(30.0 \%$ vs. $11.0 \%, p=0.03)$. Moreover, there were no significant differences between the two groups in age, sex, ISS, time to AE, fracture classification, volume of blood transfusion, or rate of repeat $\mathrm{AE}$. We speculate that patients without signs of CE during CT would have been experiencing shock due to causes other than arterial injury, such as cancellous fracture surface bleeding or venous plexus bleeding. As a result, AE may have provided little benefit in these patients, while delaying the resuscitation procedure and potentially increasing the risk of mortality. Therefore, AE should not be a routine procedure for hemodynamically unstable patients with unstable pelvic fractures, and other hemostasis procedures, such as PPP, should be considered during the resuscitation process for these patients.

Although we made every effort to reduce the influence of bias in this study, it has several limitations. First, the retrospective design is inherently associated with risks of bias, and we observed that cases that underwent $\mathrm{AE}$ were more severe and had higher ISS scores than the non-AE cases. Thus, the higher complication rate in the $\mathrm{AE}$ group might reflect the severity of the patients' injuries, and strict selection criteria may be needed for the $\mathrm{AE}$ procedure to avoid further complications that are difficult to manage. Second, although our center uses an established protocol to identify patients who should undergo angiography, the choice of selective or nonselective embolization was at the radiologist's discretion. The interventional radiologists commonly noted that non-selective embolization was performed "to facilitate hemostasis," even when no arterial bleeding was identified during angiography. Third, AE has been performed at our center during the last two decades as part of a fixed protocol for hemodynamically unstable patients with pelvic fractures, and it may be difficult to encourage experienced emergency traumatologists to include PPP as an alternative strategy in our resuscitation protocol.

\section{Conclusions}

In conclusion, we believe that angioembolization is an effective, time-saving, and readily available procedure for pelvic fracture-related arterial hemorrhage. However, given the high rate of SSIs, non-selective AE may not be the best practice in this setting when there is no sign of $\mathrm{CE}$ during $\mathrm{CT}$ or when the patient does not respond to resuscitation after other sources of hemorrhage have been excluded. It may be appropriate to perform more selective or super-selective embolization procedures in carefully selected patients and to consider PPP as an alternative hemostasis strategy in the resuscitation protocol when there are no imaging-based signs of arterial bleeding.

\section{Abbreviations}

AE: Arterial embolization; CE: Contrast extravasation; CT: Computed tomography; ED: Emergency department; ISS: Injury severity score; NPV: Negative predictive value; nBIIAE: Nonselective bilateral internal iliac artery embolization; SSI: Surgical site infection; PPP: Preperitoneal pelvic packing; PPV: positive predictive value; SSI: Surgical site infection

\section{Acknowledgments}

Not applicable.

\section{Authors' contributions}

Study conception and design: I.-C.T., C.-Y.S., and Y.-H.Y.; study performance: C.-Y.L. and Y.-H.Y.; writing of the manuscript: C.-Y.L. and Y.-H.Y; manuscript review and editing: Y.-H.H., Y.-C.C., and W.-L.Y.; study supervision: Y.-H.Y. All authors have read and approved the final version of the manuscript. 


\section{Funding}

Not applicable.

\section{Availability of data and materials}

All data generated and analyzed during this study are included in the published article.

\section{Ethics approval and consent to participate}

The study protocol was approved by the institutional review board of Chang Gung Medical Foundation (201802139B0) and complied with the Good

Clinical Practice guidelines and applicable laws and regulations.

\section{Consent for publication}

Not applicable.

\section{Competing interests}

The authors declare that they have no competing interests.

\section{Author details}

'Department of Orthopedic Surgery, Musculoskeletal Research Center, Chang Gung Memorial Hospital, Linkou branch, and Chang Gung University 33302 Tao-Yuan, Taiwan. 5, Fu-Hsin St. Kweishan, 33302 Tao-Yuan, Taiwan. 2Department of Orthopedic Surgery, Chang Gung Memorial Hospital, Keelung Branch, and Chang Gung University, Keelung City, Taiwan. ${ }^{3}$ Department of Medical Imaging \& Intervention, Chang Gung Memorial Hospital, Linkou Branch, and Chang Gung University, Taoyuan City, Taiwan.

Received: 25 December 2019 Accepted: 27 May 2020

Published online: 30 May 2020

\section{References}

1. Hou Z, Smith WR, Strohecker KA, Bowen TR, Irgit K, Baro SM, et al. Hemodynamically unstable pelvic fracture management by advanced trauma life support guidelines results in high mortality. Orthopedics. 2012; 35:319-24

2. Godinho M, Garcia Dde F, Parreira JG, Fraga GP, Nascimento B, Rizoli S. Management of hemorrhage in patients with pelvic fracture and hemodynamically unstable. Rev Col Bras Cir. 2012;39:238-42.

3. Stein DM, O'Toole R, Scalea TM. Multidisciplinary approach for patients with pelvic fractures and hemodynamic instability. Scand J Surg. 2007;96:272-80.

4. Cullinane DC, Schiller HJ, Zielinski MD, Bilaniuk JW, Collier BR, Como J, et al. Eastern Association for the Surgery of trauma practice management guidelines for hemorrhage in pelvic fracture--update and systematic review. J Trauma. 2011:71:1850-68.

5. Katsura M, Yamazaki S, Fukuma S, Matsushima K, Yamashiro T, Fukuhara S. Comparison between laparotomy first versus angiographic embolization first in patients with pelvic fracture and hemoperitoneum: a nationwide observational study from the Japan trauma data Bank. Scand J Trauma Resusc Emerg Med. 2013;21:82.

6. Comai A, Zatelli M, Haglmuller T, Bonatti G. The role of Transcatheter arterial embolization in traumatic pelvic hemorrhage: not only pelvic fracture. Cureus. 2016;8:e722.

7. Fu CY, Chan SY, Wang SY, Hsieh CH, Liao CH, Huang JF, et al. The effect of angioembolization for life-threatening retroperitoneal hemorrhage in patients with pelvic fracture. Am J Emerg Med. 2019;37:603-7.

8. Hauschild O, Aghayev E, von Heyden J, Strohm PC, Culemann U, Pohlemann T, et al. Angioembolization for pelvic hemorrhage control: results from the German pelvic injury register. J Trauma Acute Care Surg. 2012;73:679-84

9. Morozumi J, Homma H, Ohta S, Noda M, Oda J, Mishima S, et al. Impact of mobile angiography in the emergency department for controlling pelvic fracture hemorrhage with hemodynamic instability. J Trauma. 2010;68:90-5.

10. Kuo LW, Yang SJ, Fu CY, Liao CH, Wang SY, Wu SC. Relative hypotension increases the probability of the need for angioembolisation in pelvic fracture patients without contrast extravasation on computed tomography scan. Injury. 2016:47:37-42.

11. Manson TT, Perdue PW, Pollak AN, O'Toole RV. Embolization of pelvic arterial injury is a risk factor for deep infection after acetabular fracture surgery. J Orthop Trauma. 2013;27:11-5.
12. Lindvall E, Davis J, Martirosian A, Garcia G, Husak L. Bilateral internal iliac artery embolization results in an unacceptably high rate of complications in patients requiring pelvic/Acetabular surgery. J Orthop Trauma. 2018;32:445-51.

13. Ramin S, Hermida M, Millet I, Murez T, Monnin V, Hamoui M, et al. Limits of intravascular contrast extravasation on computed tomography scan to define the need for pelvic angioembolization in pelvic blunt trauma: a specific assessment on the risk of false positives. J Trauma Acute Care Surg. 2018;85:527-35

14. Faringer PD, Mullins RJ, Feliciano PD, Duwelius PJ, Turnkey DD. Selective fecal diversion in complex open pelvic fractures from blunt trauma. Arch Surg. 1994:129:958-63.

15. Tesoriero RB, Bruns BR, Narayan M, Dubose J, Guliani SS, Brenner ML, et al. Angiographic embolization for hemorrhage following pelvic fracture: is it "time" for a paradigm shift? J Trauma Acute Care Surg. 2017;82:18-26.

16. Matsushima K, Piccinini A, Schellenberg M, Cheng V, Heindel P, Strumwasser $A$, et al. Effect of door-to-angioembolization time on mortality in pelvic fracture: every hour of delay counts. J Trauma Acute Care Surg. 2017;84: 685-92.

17. Brasel KJ, Pham K, Yang H, Christensen R, Weigelt JA. Significance of contrast extravasation in patients with pelvic fracture. J Trauma. 2007;62 1149-52.

18. Lai YC, Wu CH, Chen HW, Wang LJ, Wong YC. Predictors of active arterial hemorrhage on angiography in pelvic fracture patients. Jpn J Radiol. 2018; 36:223-30.

19. Verbeek DO, Zijlstra IA, van der Leij C, Ponsen KJ, van Delden OM, Goslings JC. Management of pelvic ring fracture patients with a pelvic "blush" on early computed tomography. J Trauma Acute Care Surg. 2014;76:374-9.

20. Juern JS, Milia D, Codner P, Beckman M, Somberg L, Webb T, et al. Clinical significance of computed tomography contrast extravasation in blunt trauma patients with a pelvic fracture. J Trauma Acute Care Surg. 2017;82: $138-40$

21. Barentsz MW, Vonken EP, van Herwaarden JA, Leenen LP, Mali WP, van den Bosch MA. Clinical outcome of intra-arterial embolization for treatment of patients with pelvic trauma. Radiol Res Pract. 2011;2011:935484.

22. Dreizin D, Bodanapally U, Boscak A, Tirada N, Issa G, Nascone JW, et al. CT prediction model for major arterial injury after blunt pelvic ring disruption. Radiology. 2018:287:1061-9.

23. Scemama U, Dabadie A, Varoquaux A, Soussan J, Gaudon C, Louis G, et al. Pelvic trauma and vascular emergencies. Diagn Interv Imaging. 2015;96:717-29.

24. Auerbach AD, Rehman S, Kleiner MT. Selective transcatheter arterial embolization of the internal iliac artery does not cause gluteal necrosis in pelvic trauma patients. J Orthop Trauma. 2012;26:290-5.

25. Hymel A, Asturias S, Zhao F, Bliss R, Moran T, Marshall RH, et al. Selective versus nonselective embolization versus no embolization in pelvic trauma: a multicenter retrospective cohort study. J Trauma Acute Care Surg. 2017;83: 361-7.

26. Joshi AR, Komwad AL, Joshi SA. Role of $C T$ in abdominal and pelvic trauma. Curr Radiol Rep. 2014;2:67.

\section{Publisher's Note}

Springer Nature remains neutral with regard to jurisdictional claims in published maps and institutional affiliations.

Ready to submit your research? Choose BMC and benefit from:

- fast, convenient online submission

- thorough peer review by experienced researchers in your field

- rapid publication on acceptance

- support for research data, including large and complex data types

- gold Open Access which fosters wider collaboration and increased citations

- maximum visibility for your research: over $100 \mathrm{M}$ website views per year

At BMC, research is always in progress.

Learn more biomedcentral.com/submissions 